\title{
Domiciliary liquid oxygen versus concentrator treatment in chronic hypoxaemia: a cost-utility analysis
}

\author{
A. Andersson*, K. Ström**, H. Brodin+, M. Alton++, G. Boman§, P. Jakobsson ${ }^{\ddagger}$, A. Lindberg\$, \\ M. Uddenfeldt", H. Walterli, L-Å. Levin*
}

Domiciliary liquid oxygen versus concentrator treatment in chronic hypoxaemia: a costutility analysis. A. Andersson, K. Ström, H. Brodin, M. Alton, G. Boman, P. Jakobsson, A. Lindberg, M. Uddenfeldt, H. Walter, L-Å. Levin. OERS Journals Ltd 1998.

ABSTRACT: Whether long-term oxygen therapy (LTOT) improves quality of life in chronic hypoxaemia has been questioned. LTOT with an oxygen concentrator $(\mathrm{C} / \mathrm{C})$ and gas cylinders for ambulation is considered cumbersome compared to mobile liquid oxygen equipment $(\mathrm{L})$. The hypothesis for this study was that LTOT with liquid oxygen treatment $(L)$ improves patients' health-related quality of life, but that it is also more expensive compared to concentrator $(\mathrm{C} / \mathrm{C})$ treatment.

A prospective, randomized multicentre trial comparing $C / C$ with $L$ for LTOT was conducted during a six-month period. Fifty-one patients $(29$ on $\mathrm{L}$ and 22 on $\mathrm{C} / \mathrm{C})$ with chronic hypoxaemia, regularly active outside the home, participated in the study initially. Costs for oxygen were obtained from the pharmacies. Patient diaries and telephone contacts with members of the healthcare sector were used to estimate costs. Health-related quality of life was measured by the Sickness Impact Profile (SIP) and the EuroQol, instruments at the start and after 6 months.

The average total cost per patient for group $\mathrm{C} / \mathrm{C}$ for the six-month period was US\$1,310, and for group $L$ it was US\$4,950. Health-related quality of life measured by the SIP instrument showed significant differences in favour of group $L$ in the categories/dimensions of physical function, body care, ambulation, social interaction and total SIP score.

In conclusion, liquid-oxygen treatment was more expensive compared to concentrator treatment. However, treatment effects showed that liquid oxygen had a better impact on quality of life.

Eur Respir J 1998; 12: 1284-1289.

New medical technology is creating increased possibilities for advanced home care in many areas previously requiring inhospital care. Advanced home care is one alternative that might constitute a strategy for increasing efficiency in the healthcare sector and for solving some of the problems faced today. There are no studies to date proving that this is always the case, although many are in progress $[1,2]$. In a recent Canadian study [3], it was concluded that the quality of existing research is somewhat questionable, and that the cost-effectiveness of home care must be considered on a case-by-case basis for each type of intervention.

For patients with chronic hypoxaemia and chronic obstructive pulmonary disease (COPD), long-term oxygen treatment (LTOT) increases survival rates if oxygen is used for at least $15 \mathrm{~h} \cdot \mathrm{day}^{-1}[4,5]$. However, the impact on patients' quality of life (QoL) is a matter of debate [6, 7]. Results from the National Swedish Oxygen Register show that sufficient patient compliance is not always attained [8]. Thirty per cent of the patients who are prescribed oxygen for a minimum of $15 \mathrm{~h} \cdot$ day $^{-1}$ actually use it for shorter periods of time [8]. This lack of compliance, which has also been observed by other investigators, can be expected to result in lower survival rates than would otherwise be possible, and in unnecessary morbidity requiring hospital care $[5,9]$.
*Center for Medical Technology Assessment, Linköping University, Sweden. **Division of Lung Medicine, Blekinge Hospital Karlskrona, University of Lund, Sweden. +Biopharmacy and Pharmacokinetics, Uppsala University, Sweden. ++Dept of Lung Medicine, Örebro Hospital, Sweden. §Dept of Lung Medicine, Akademiska sjukhuset, Uppsala University, Sweden. Medicine, University Hospital, Linköping, Sweden. \$Dept of Lung Medicine, Boden Hospital, Sweden. \#Dept of Lung Medicine Gävle Hospital, Sweden. IDept of Lung Medicine, Karolinska Hospital, Solna, Sweden.

Correspondence: A. Andersson, Center for Medical Technology Assessment, Linköping University, S-581 83 Linköping, Sweden, Fax: 4613282995

Keywords: Cost, efficiency, home care, longterm oxygen therapy, quality of life, utility

Received: March 41998

Accepted after revision September 301998

Supported by AGA Gas Ltd., Sweden and The National Pharmacy Corporation's fund for research and studies in health economics and social pharmacy.
Two main regimens are available for oxygen administration to patients with hypoxaemia. In Sweden, the standard therapy is concentrator treatment $(\mathrm{C} / \mathrm{C})$, although liquid oxygen $(\mathrm{L})$ has been introduced in recent years. The most frequent complaint patients make about concentrator treatment is that it makes them feel tied down [10]. Liquid oxygen, however, is four times as concentrated as gas in a high-pressure cylinder. The containers are relatively small and light, but still contain enough oxygen to last for a longer period of time. Patients can easily refill the portable container from a stationary container whenever necessary. Long-term liquid oxygen treatment is considered to be more expensive than concentrator treatment.

The aim of this study was to compare the two main regimens for oxygen administration in LTOT in the home for patients with COPD. The hypothesis of this study was that LTOT with $\mathrm{L}$ has a better impact on QoL, but that it is also more expensive compared to LTOT with $\mathrm{C} / \mathrm{C}$ treatment.

\section{Material and methods}

\section{Study design}

The study was a prospective, randomized multicentre trial comparing concentrator treatment with small oxygen 
cylinders for ambulation $(\mathrm{C} / \mathrm{C})$ to liquid oxygen treatment (L). A cost-utility analysis was used that involved comparing the costs of a healthcare programme with the utilities gained or lost. The healthcare utilities were reflected by the EuroQol instrument and the Sickness Impact Profile (SIP) (see "Quality of life" section below for further details). Patients were randomized to $\mathrm{C} / \mathrm{C}$ or $\mathrm{L}$ for a sixmonth period. Some patients in both groups also received occasional complementary treatment with compressed gas. The study was reviewed and approved by the research ethics committee.

\section{Patient data}

The data collection started in 1993/1994. The study was planned as an ancillary study to The Swedish Oxygen Register, in which $85 \%$ of all patients in Sweden receiving LTOT for chronic hypoxaemia were followed [11].

Fifty-one patients from six different departments of pulmonary medicine in Sweden were randomized to the two alternative treatments. The inclusion criteria were chronic hypoxaemia caused by pulmonary disease (the cut-off point for hypoxemia was $7.0-7.5 \mathrm{kPa}$ or, in the presence of signs of cor pulmonale or haematocrit above $50 \%$, around $7.5 \mathrm{kPa}$ ), eligibility for treatment with liquid oxygen, the ability to use mobile equipment outside the home, and a need or desire to spend time outside the home on a weekly basis. Patients who already received oxygen treatment at home could also be included in the trial. Exclusion criteria were being unable to leave the home or being unable to use mobile oxygen equipment. The recommended oxygen flow rate was continuous oxygen flow for a minimum of $16 \mathrm{~h}$, preferably $24 \mathrm{~h}$, achieving an arterial oxygen tension $\left(\mathrm{Pa}_{\mathrm{a}} \mathrm{O}_{2}\right)$ when breathing oxygen of $>8 \mathrm{kPa}$.

The data concerning consumption of liquid oxygen and, for a few patients, small amounts of gas oxygen, were collected from invoices sent by the gas company to the local pharmacies ordering the delivery of oxygen to the patients. The total cost of liquid oxygen consists of several components: the cost of the oxygen itself, the cost of delivery (when these data were collected, the gas company had different tariffs depending on the distance travelled to deliver the oxygen), and rental of the stationary container. Depreciation costs for the portable container were estimated. The costs of various complementary equipment like nasal catheters and assistive devices were not included in the data collection.

During the six-month period, the patients were asked to keep a "diary" in which they registered their contacts (visits or telephone consultations) with physicians, nurses, physical therapists, almoners, medical technicians (MT), as well as their use of transportation services. The diary notes regarding the patients' visits and/or telephone contacts with physicians, nurses, physical therapists, almoners, and their use of transportation services, were used to estimate costs during the trial.

The MT at each hospital kept records of the time spent on device services for each patient during the study period and, if possible, also made an estimate of the attributable costs. Data concerning the patient's contacts with MTs were excluded from the diary and the more reliable information received directly from the MTs, described above, was used instead. The estimation of the cost of the use of resources registered in the patient diaries was made retrospectively, using information collected from each department involved in the study. A median cost was calculated for each category.

Cost items were summarized using the following expression. All costs are expressed in 1996 prices. Value added tax was not included.

Total cost $=\left(\right.$ number of $\mathrm{O}_{2}$ tanks $\times$ cost $)+($ number of freights $\times$ cost $)+($ number of days with rent for the stationary container, $\mathrm{L} \times \operatorname{cost})+($ number of services $\times$ cost $)+$ depreciation portable unit/depreciation concentrator + cost estimated by the diary $+(($ MT time+travel time $) \times$ cost $)$.

For the $\mathrm{C} / \mathrm{C}$ patients, the concentrators received maintenance service by the MT twice a year on average, or after about 3,000 h. One service was estimated to cost between US\$234-260. The hospitals buy the concentrators at a cost regulated by the procurement company of the Swedish principals of health and medical care [12]. The average cost of a concentrator was calculated at US\$3,510. This entails a depreciation cost of US\$351 for the six-month period using the traditional method of historic cost depreciation [13], i.e. by dividing the amount that was actually paid by the hospital for the concentrator by the years of its life, which has been estimated in this case to be 5 yrs.

A similar estimation was made for the cost of the portable container for group L. This means that there was a depreciation cost of US\$130 for the six-month period (the amount actually paid was US\$1,300, with an estimated 5 yr lifetime).

The same cost was used for both visits and telephone consultations. The transportation service cost was estimated using information from the local taxi company responsible.

\section{Quality of life}

The quality of life analysis was based on 47 patients (27 $\mathrm{L}$ and $20 \mathrm{C} / \mathrm{C}$ ) for whom satisfactory data were collected. The SIP and the EuroQol instruments were used at the start of the trial and after 6 months in order to measure patient outcome. The SIP [14] contains several dimensions of importance to health-related QoL that can be weighted together into one single score. The higher the score, the worse the QoL. The instrument is generic, and might therefore be insensitive to specific changes in a patient's QoL.

The EuroQol [15] is an instrument developed for measuring health-related utility scores used in cost-utility analyses. The categories/dimensions of mobility, self-care, usual activity, pain, discomfort, anxiety/depression and better/worse are graded on three levels. The three levels reflect increasing degrees of difficulty, i.e. level $1=$ no problem, level $2=$ some or moderate problems, and level 3 = unable or extreme problems. The scores for the six categories/dimensions should therefore be interpreted as the lower the score, the better the QoL. The score for the scale should be interpreted as the higher the score, the better the QoL. 
Table 1. - Demographic and clinical data at the start of the trial (mean \pm sD, $n=51)$

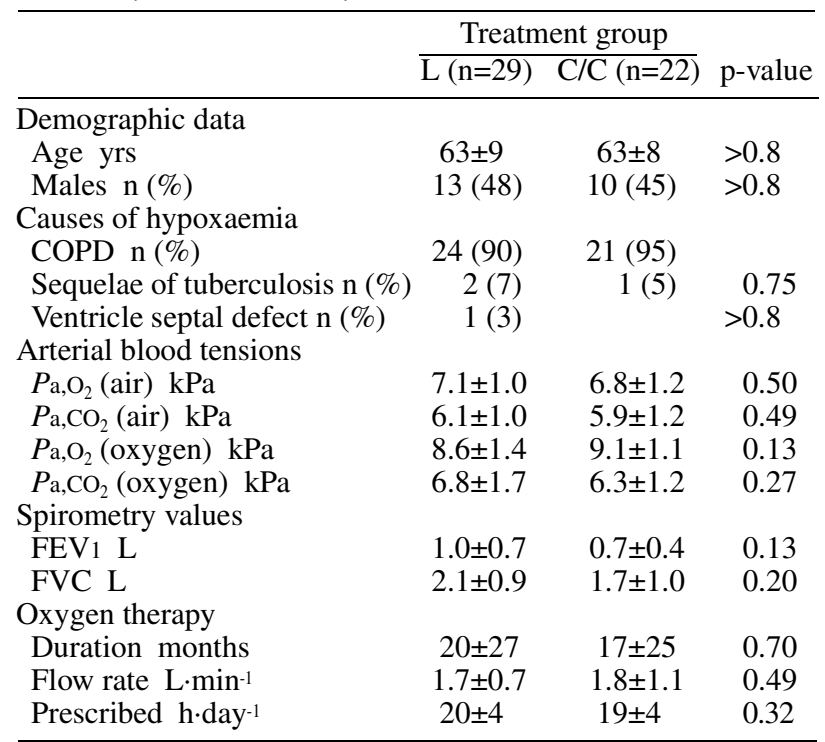

L: liquid oxygen; C/C: oxygen concentrator; COPD: chronic obstructive pulmonary disease; $P \mathrm{a}, \mathrm{O}_{2}$ : arterial oxygen tension; $P_{\mathrm{a}}, \mathrm{CO}_{2}$ : arterial carbon dioxide tension; $\mathrm{FEV}_{1}$ : forced expiratory volume in one second; FVC: forced vital capacity.

\section{Statistical analysis}

The statistic analysis was performed using SPSS 6.1 for Windows (SPSS, Chicago, IL, USA). Throughout the analysis t-tests were used to compare the two treatment groups. A one-sided p-value $(<0.05)$ was considered significant.

\section{Results}

In group L, one patient discontinued treatment with liquid oxygen after 48 days for personal reasons. Two patients, one in each group, died during the study period, one after 17 days of treatment $(\mathrm{C} / \mathrm{C})$ and one after 4 months of treatment $(\mathrm{L})$.

At the start of the trial, the following data were collected: age, sex, arterial blood gas tensions on air and oxygen, spirometry values, causes of hypoxaemia, oxygen treatment including flow rate, hours per day, duration of LTOT prior to trial, and need for assistance with oxygen equipment.
There were no significant differences between the groups in terms of age, sex, cause of hypoxaemia, arterial blood gas tensions, oxygen therapy or spirometry values at the start of the trial (all p $>0.10$ ) (table 1). Thirty-two patients had chronic hypoxaemia caused by COPD, with a $\mathrm{Pa}_{\mathrm{a}} \mathrm{O}_{2}$ $<7.4 \mathrm{kPa}$.

Chronic hypoxaemia was caused by COPD in all but four patients, three of whom had sequelae from pulmonary tuberculosis and one of whom had a ventricular septal defect.

Costs

Calculation of the costs was based on 48 patients $(27 \mathrm{~L}$ and $21 \mathrm{C} / \mathrm{C}$ ) for whom satisfactory data were collected, although the diary was correctly filled out by only 45 patients $(24 \mathrm{~L}$ and $21 \mathrm{C} / \mathrm{C})$. The costs include direct monetary costs of different services as well as costs for equipment and oxygen. The aim was to estimate, if possible, the short-term marginal costs. All costs are expressed in US\$, 1996 prices. The diaries showed only slight differences in the healthcare profiles and the estimated costs of the two groups. Forty per cent of the patients in group L used MT services during the trial for an average of $190 \mathrm{~min}$, and $91 \%$ of those in group C/C used MT services for an average of 202 min (tables 2 and 3).

Some patients in both groups used compressed gas as a complementary treatment. The cost of compressed gas was on average US\$130 for these patients during the sixmonth period. This cost is included in the total cost for oxygen in table 4.

The mean total cost per patient per six-month period in group C/C was US\$1,310, and for group L, it was US $\$ 4,950$. The patients receiving treatment with liquid oxygen consumed on average $23( \pm 14)$ containers ( $30 \mathrm{~L}$ each) during the six-month period.

\section{Quality of life}

The SIP and the EuroQol instrument were correctly completed by 45 patients, but had to be discarded for four patients due to inadequate answers.

Health-related QoL as measured by the SIP Instrument is shown in table 4. Each dimension is presented separately, as well as the total SIP scores for the two respective groups.

Table 2. - Average consumption and cost estimate of healthcare services per patient for visits/phone contacts during a six-month period per 1996 prices (US\$)

\begin{tabular}{|c|c|c|c|c|c|}
\hline & \multicolumn{2}{|c|}{ Time $\min$} & \multicolumn{2}{|c|}{ Cost estimate US\$ } & \multirow[b]{2}{*}{ p-value } \\
\hline & $\mathrm{L}$ & $\mathrm{C} / \mathrm{C}$ & $\overline{\mathrm{L}}$ & $\mathrm{C} / \mathrm{C}$ & \\
\hline Physician visits & $75 \pm 83$ & $177 \pm 226$ & $52 \pm 57$ & $122 \pm 156$ & 0.061 \\
\hline Phone & $4 \pm 9$ & $8 \pm 16$ & $3 \pm 6$ & $6 \pm 11$ & 0.324 \\
\hline Nurse visits & $159 \pm 175$ & $187 \pm 168$ & $46 \pm 51$ & $55 \pm 49$ & 0.580 \\
\hline Phone & $35 \pm 46$ & $22 \pm 32$ & $10 \pm 13$ & $7 \pm 9$ & 0.290 \\
\hline Physiotherapist visits & $77 \pm 217$ & $58 \pm 150$ & $23 \pm 64$ & $17 \pm 44$ & 0.735 \\
\hline Phone & $4 \pm 12$ & $1 \pm 4$ & $1 \pm 4$ & $0.24 \pm 1$ & 0.273 \\
\hline Almoner visits & $11 \pm 40$ & $3 \pm 10$ & $3 \pm 12$ & $1 \pm 3$ & 0.369 \\
\hline Phone & $4 \pm 15$ & $2 \pm 7$ & $1 \pm 4$ & $0.53 \pm 2$ & 0.497 \\
\hline Transport service & $356 \pm 625$ & $203 \pm 481$ & $193 \pm 339$ & $110 \pm 261$ & 0.361 \\
\hline Medical technician & $190 \pm 120$ & $202 \pm 117$ & $110 \pm 70$ & $118 \pm 68$ & 0.777 \\
\hline
\end{tabular}

L: liquid oxygen treatment group $(n=24) ; C / C$ : oxygen concentrator treatment group $(n=21)$. 
Table 3. - Total treatment cost distributed over the two subgroups at 1996 prices (US\$); mean \pm SD during a sixmonth period

\begin{tabular}{lcc}
\hline Type of cost & $\mathrm{L}(\mathrm{n}=27)$ & $\mathrm{C} / \mathrm{C}(\mathrm{n}=21)$ \\
\hline Oxygen & $2200 \pm 1360$ & $260 \pm 500$ \\
Rent, freight and depreciation & $3340 \pm 2650$ & $500 \pm 280$ \\
Consumption of healthcare services & $390 \pm 370$ & $340 \pm 350$ \\
Medical technician & $110 \pm 70$ & $120 \pm 70$ \\
Total cost* & $4950 \pm 2340$ & $1310 \pm 650$ \\
\hline
\end{tabular}

L: liquid oxygen treatment group; C/C: oxygen concentrator treatment group. ${ }^{*}$ : owing to missing values, the total cost for the different subgroups is not equal to the mean total cost.

Group L attained improvement in 13 out of 15 categories/dimensions. A slight deterioration can be noted only in the categories of eating and home management. Group $\mathrm{C} / \mathrm{C}$ attained improvement in only four categories/dimensions. None of these changes was significant, however.

The final column in table 4 shows the results of a comparison of the changes (before - after) in health in the two groups. Significant differences between the two groups were found in four categories/dimensions and in total SIP scores. Group L showed an improvement in these categories/dimensions, whereas group $\mathrm{C} / \mathrm{C}$ became worse.

A subanalysis, regarding QoL measured by the SIP instrument, for COPD patients with a $\mathrm{Pa}_{\mathrm{a}} \mathrm{O}_{2}$ on air of $<7.4$ $\mathrm{kPa}$ was performed $(\mathrm{n}=15$ for group $\mathrm{L}$ and $\mathrm{n}=10$ for group $\mathrm{C} / \mathrm{C}$ ). A comparison of the changes (before - after) in health of the groups showed significant changes in five categories/dimensions (body care, ambulation, psychosocial function, sleep and total SIP score). Group L showed an improvement in all but one of these categories/dimensions, whereas group $\mathrm{C} / \mathrm{C}$ became worse. In the sleep category, both groups became worse, and group L worsened more than group $\mathrm{C} / \mathrm{C}$.

Health-related QoL, was measured by the EuroQol instrument, is shown in table 5. The scores are shown as average/mean numbers. The score of the scale should be interpreted as the higher the score, the better the QoL.
In this study, the improvements observed in the SIP were not as obvious in the EuroQol. Group L showed some improvement in all categories/dimensions, and group $\mathrm{C} / \mathrm{C}$ showed an improvement only in the categories/dimensions of usual activity and better/worse. However, the results of comparing the changes (before - after) in health between the two groups show no significant differences.

\section{Discussion}

This study showed that liquid oxygen treatment was more expensive than concentrator treatment, but had a better impact on QoL. The patients included in this trial were all eligible for both treatment alternatives. If the $\mathrm{C} / \mathrm{C}$ group had instead received liquid oxygen, the cost would have increased almost four-fold. The main part of this cost would consist of an increased oxygen supply. However, the QoL for these patients would have improved slightly instead of deteriorating. Whether this is justifiable or not constitutes a policy issue.

The cost estimates of the study are based on careful calculations. However, some opportunity cost assumptions had to be made. Firstly, many scale factors are present in the process, which makes it difficult 1) to separate certain patient specific costs, and 2) to judge whether or not the size of the hospital affects the costs. An example of the first is that some technicians go to the patient's home and service the concentrator there, or exchange the concentrator for an already-serviced machine. Some MTs service the equipment every 6 months, and, for some patients in the study, the service was carried out just before or just after the trial period. Therefore, a six-month trial period is likely to be too short in order to attain a true estimation of the use of MT services.

In this study, the improvements observed in the SIP were not seen in the EuroQol. It is impossible to say whether this is an effect of the EuroQol being a poor instrument for measuring the kind of changes in QoL important to these patient groups, or whether the treatment in both groups is

Table 4. - Health-related quality of life measured by the Sickness Impact Profile (SIP) instrument before and after the trial

\begin{tabular}{|c|c|c|c|c|c|c|c|}
\hline \multirow[b]{2}{*}{ Category/dimension } & \multicolumn{3}{|c|}{$L(n=25)$} & \multicolumn{3}{|c|}{$C / C(n=20)$} & \multirow{2}{*}{$\begin{array}{l}\text { ýC/C-ýL } \\
\text { p-value }\end{array}$} \\
\hline & Before & After & ý & Before & After & ý & \\
\hline Physical function* & 11.46 & 9.93 & 1.53 & 8.27 & 11.31 & -3.04 & 0.043 \\
\hline Mobility & 12.25 & 11.77 & 0.48 & 9.49 & 11.16 & -1.67 & 0.308 \\
\hline Body care & 7.55 & 4.42 & 3.13 & 4.26 & 6.96 & -2.70 & 0.011 \\
\hline Ambulation & 20.62 & 18.09 & 2.53 & 16.74 & 22.67 & -5.93 & 0.017 \\
\hline Psychosocial function* & 5.41 & 4.98 & 0.43 & 4.39 & 6.04 & -1.65 & 0.082 \\
\hline Emotional behaviour & 7.59 & 5.83 & 1.76 & 4.96 & 6.33 & -1.37 & 0.135 \\
\hline Social interaction & 7.96 & 6.09 & 1.87 & 7.18 & 10.58 & -3.40 & 0.023 \\
\hline Alertness & 5.51 & 5.12 & 0.39 & 0.54 & 3.62 & -3.08 & 0.064 \\
\hline Communication & 2.22 & 1.79 & 0.43 & 2.46 & 2.46 & - & 0.333 \\
\hline Independent categories* & - & - & & - & - & & - \\
\hline Work & 49.93 & 44.05 & 5.88 & 37.55 & 32.94 & 4.61 & 0.416 \\
\hline Sleep & 15.26 & 10.32 & 4.94 & 15.18 & 14.42 & 0.76 & 0.150 \\
\hline Eating & 1.07 & 1.95 & -0.88 & 1.16 & 2.70 & -1.54 & 0.276 \\
\hline Home management & 25.90 & 26.52 & -0.62 & 28.28 & 24.93 & 3.35 & 0.230 \\
\hline Recreation & 28.07 & 19.34 & 8.73 & 29.22 & 28.33 & 0.89 & 0.065 \\
\hline Total SIP score & 10.22 & 8.64 & 1.58 & 8.48 & 10.28 & -1.80 & 0.018 \\
\hline
\end{tabular}

L: liquid oxygen treatment; C/C. oxygen concentrator treatment *. the categories indicated show a weighted score for the dimensions within one category, e.g. the category "physical function" is a weighted score for the dimensions mobility, body care and ambulation; ý: shows the change in quality of life, i.e. before minus after, with positive values indicating an improvement in quality of life. 
Table 5. - Health-related quality of life measured by the EuroQol instrument (mean) before and after the trial

\begin{tabular}{|c|c|c|c|c|c|c|c|}
\hline \multirow[b]{2}{*}{ Category/dimension } & \multicolumn{3}{|c|}{$\mathrm{L}(\mathrm{n}=25)$} & \multicolumn{3}{|c|}{$\mathrm{C} / \mathrm{C}(\mathrm{n}=20)$} & \multirow{2}{*}{$\begin{array}{l}\text { ýC/C-ýl } \\
\text { p-value }\end{array}$} \\
\hline & Before & After & ý & Before & After & ý & \\
\hline Mobility & 1.35 & 1.31 & 0.04 & 1.21 & 1.21 & - & 0.394 \\
\hline Self-care & 1.00 & 1.00 & - & 1.00 & 1.00 & - & 0.110 \\
\hline Usual activity & 1.78 & 1.74 & 0.04 & 1.71 & 1.50 & 0.21 & 0.298 \\
\hline Pain/discomfort & 1.79 & 1.70 & 0.09 & 1.87 & 2.00 & -0.13 & 0.069 \\
\hline Anxiety/depression & 1.31 & 1.19 & 0.12 & 1.35 & 1.41 & -0.06 & 0.061 \\
\hline Better/worse & 2.15 & 1.81 & 0.34 & 2.22 & 2.00 & 0.22 & 0.185 \\
\hline Scale & 50.76 & 53.40 & -2.64 & 53.53 & 53.29 & 0.24 & 0.217 \\
\hline
\end{tabular}

L: liquid oxygen treatment group; $\mathrm{C} / \mathrm{C}$ : oxygen concentrator treatment group. ý: change in quality of life, i.e. before - after.

in fact very similar regarding quality of life. A recent study [14] compares outcome measures for patients with COPD in an outpatient setting. The results suggest that the EuroQol is less appropriate for use in this patient group, although the EuroQol rating scale was responsive to health changes. In this study, the SIP scores indicate that liquid oxygen appears to have a better impact on QoL compared to the concentrator and small cylinders for ambulation in mobile patients with LTOT.

The finding that LTOT with a concentrator did not improve QoL is in complete accordance with the results of OкuBADEjo et al. [7], who found no improvement after 6 months of concentrator treatment in 23 COPD patients with a $P \mathrm{a}, \mathrm{O}_{2}$ on air of $<7.3 \mathrm{kPa}$, or $<8.0 \mathrm{kPa}$ when evidence of cor pulmonale was present. These patients ( 15 females, eight males) had a similar degree of hypoxaemia and a mean forced expiratory volume in one second (FEV1) of $0.75 \mathrm{~L}$. The mean FEV 1 value for our COPD patients was $0.91 \mathrm{~L}$, a higher value that might be explained in part by the higher proportion of males in our trial. The higher FEV1 value and better SIP values in our patients in this study could also be explained by the fact that only patients who were regularly active outside the home were selected. It would have been pointless to investigate the effect of a more expensive treatment in patients who could not benefit from its advantages.

A significant difference in change in QoL between the treatment groups was found. For mobile patients, regularly active outside the home, it is therefore thought that $\mathrm{L}$ is a better treatment alternative than $\mathrm{C} / \mathrm{C}$. This significant difference was found in patients with COPD and a $\mathrm{Pa}, \mathrm{O}_{2}$ of $<7.4 \mathrm{kPa}$, a patient group with unquestionable survival benefit from LTOT $[4,5,16]$. This was not found in patients with less severe hypoxaemia, some of whom had other reasons for receiving LTOT.

Improvement in QoL during LTOT could be explained by better neuropsychiatric functioning $[17,18]$ or some other effect of oxygen on an organ in a hypoxaemic patient $[19,20]$. In some patients, oxygen during exercise improves dyspnoea and/or exercise performance, important improvements for patients with severe dyspnoea on exertion [21]. Lightweight, attractive mobile oxygen equipment used outside the home could improve QoL both by being used during exertion and by being used during everyday activities.

The number of patients with COPD is increasing in many countries. In the USA, for example, it is now one of the main causes of death. The proportion of males and females starting LTOT in Sweden was approximately equal in 1995. Since then, smoking and the incidence of lung cancer have decreased in males, whereas both have increased in females. An increase in the number of females with chronic hypoxaemia in Sweden can therefore be expected.

In conclusion, liquid-oxygen treatment is more expensive than concentrator treatment. However, treatment effects show that liquid oxygen has a better impact on the patients quality of life. A transfer from concentrator treatment to liquid oxygen would increase the costs of financing bodies but would also lead to a higher goal fulfilment in the healthcare sector.

Acknowledgements: The authors thank A. Nordlund at Tema Health and Society, Linköping University, Sweden, for valuable advice concerning the statistical analysis.

\section{References}

1. Shepperd S, Iliffe S. Hospital at home. An uncertain future. Br Med J 1996; 12: 923-924.

2. Welch GH, Werinberg DE, Welch WP. The use of medicare home health care services. N Engl J Med 1996; 335: 324-329.

3. The cost-effectiveness of home care. A rigorous review of the literature. Saskatoon, Saskatohewan, Health Services Utilization and Research Commission, Saskatoon.

4. Medical Research Council Working Party. Long-term domiciliary oxygen therapy in chronic bronchitis and emphysema. Lancet 1981; 1: 681-686.

5. Nocturnal Oxygen Therapy. Trial Group. Continuous or nocturnal oxygen therapy in hypoxemic chronic obstructive lung disease. Ann Int Med 1980; 93: 391-398.

6. Heaton RK, Grant I, McSweeny J, Adams KM, Petty TL. Psychological effects of continuous and nocturnal oxygen therapy in hypoxaemic chronic obstructive pulmonary disease. Arch Intern Med 1983; 143: 1941-1947.

7. Okubadejo AA, Paul EA, Jones PW, Wedzicha JA. Does long-term oxygen therapy affect quality of life in patients with chronic obstructive pulmonary disease and severe hypoxaemia? Eur Respir J 1996; 9: 2335-2339.

8. Ström K, Boe J. Swedish Society of Chest Medicine. Quality assessment and predictors of survival in long- term domiciliary oxygen therapy. Eur Respir J 1991; 4: 50-58.

9. Pépin J-L, Bariffloux CE, Deschaus C, Brambilla C. Longterm oxygen therapy at home. Compliance with medical prescription and effective use of therapy. Chest 1996; 109: 1144-1150.

10. Ström K, Herala M, Boman G, Gustavil A. Assessment of two oxygen treatment alternatives in the home. Int $J$ Technol Assess Health Care 1990; 6: 489-497.

11. Ström K, Boe J. A national register for long-term oxygen therapy in chronic hypoxia: preliminary results. Eur Respir J 1988; 1: 952-958. 
12. Statistical material. Stockholm, The procurement company of the Swedish principals of health and medical care, 1996.

13. Sugden R, Williams A. The Principles of Practical Costbenefit Analysis. Oxford, Oxford University Press, 1978.

14. Bergner M, Bobbitt RA, Carter WB, Gilson BS. The Sickness Impact Profile: development and final revision of a health status measure. Med Care 1981; 19: 787-805.

15. EuroQol Group. EuroQol - a new facility for the measurement of health-related quality of life. Health Policy 1990; 16: 199-208.

16. Górecka D, Grozelak K, Sliwinski P, Toblasz M, Zielinski J. Effect of long term oxygen therapy on survival in patients with chronic obstructive pulmonary disease with moderate hypoxaemia. Thorax 1997; 52: 674-679.

17. Heaton RK, Grant I, McSweeny AJ, Adams KM, Petty TL. Psychologic effects of continuous and nocturnal oxygen therapy in hypoxemic chronic obstructive pulmonary disease. Arch Intern Med 1983; 143: 1941-1947.
18. Rourke SB, Rippeth JD, Grant I. Neuropsychiatric aspects of hypoxemia and the treatment effects of long-term oxygen therapy. In: O'Donohue WJ, eds. Long-term Oxygen Therapy. Scientific Basis and Clinical Application. Omaha, NB, Dekker, 1995; pp. 129-145.

19. Weitzenblum E, Chaouat A, Oswald M, Kessler R. The scientific basis for long-term oxygen therapy in patients with chronic hypoxemia. In: O'Donohue WJ, eds. Longterm Oxygen Therapy. Scientific Basis and Clinical Application. Omaha, NB, Dekker, 1995; pp. 25-45.

20. Aasebö U, Gyltnes A, Bremnes RM, Aakvaug A, Slørdal L. Reversal of sexual impotence in male patients with chronic obstructive pulmonary disease and hypoxemia with long term oxygen therapy. J Steroid Biochem Molec Biol 1993; 46: 799-803.

21. Celli BR. Effects of oxygen on exercise. In: O'Donohue WJ, eds. Long-term Oxygen Therapy. Scientific Basis and Clinical Application. Omaha, NB, Dekker, 1995; pp. 151-163. 